\title{
TERT promoter mutations and gene amplification: Promoting TERT expression in Merkel cell carcinoma
}

\author{
Hong Xie ${ }^{1, *}$, Tiantian Liư ${ }^{2, *}$, Na Wang ${ }^{1}$, Viveca Björnhagen ${ }^{3}$, Anders Höög1, Catharina \\ Larsson ${ }^{1}$, Weng-Onn Lui ${ }^{1}$ and Dawei $X_{u^{4}}$ \\ ${ }^{1}$ Department of Oncology-Pathology, Cancer Center Karolinska \\ 2 Department of Pathology, Shandong University School of Medicine, Jinan, PR China \\ ${ }^{3}$ Department of Reconstructive Plastic Surgery, Karolinska University Hospital Solna, Stockholm, Sweden \\ ${ }^{4}$ Department of Medicine-Solna, Division of Hematology and Center for Molecular Medicine. Karolinska Institutet and \\ Karolinska University Hospital Solna, Stockholm, Sweden \\ * These authors contributed equally to this work \\ Correspondence to: Tiantian Liu, email: liu.tiantian@outlook.com
}

Dawei Xu, email: Dawei.Xu@ki.se

Keywords: Gene amplification; Merkel cell carcinoma; MCV; Promoter mutations; Telomerase; TERT

Received: July 25, $2014 \quad$ Accepted: September 15, $2014 \quad$ Published: September 16, 2014

This is an open-access article distributed under the terms of the Creative Commons Attribution License, which permits unrestricted use, distribution, and reproduction in any medium, provided the original author and source are credited.

\section{ABSTRACT}

Telomerase activation through the induction of its catalytic component TERT is essential in carcinogenesis. The regulatory mechanism and clinical significance underlying cancer-specific TERT expression have been extensively investigated in various human malignancies, but little is known about these in Merkel cell carcinoma (MCC), an aggressive neuroendocrine skin tumor. Here we addressed these issues by determining TERT promoter mutations, gene amplification, mRNA expression and association with clinical variables in MCC. TERT mRNA was expressed in 6/6 MCC cell lines and 41 of 43 tumors derived from 35 MCC patients. Telomerase activity was detectable in all 6 cell lines and 11 tumors analyzed. TERT promoter mutations were identified in 1/6 cell lines and 4/35 (11.4\%) MCC cases. The mutation exhibited UV signature and occurred in sun-exposed areas. Increased TERT gene copy numbers were observed in $1 / 6$ cell lines and $11 / 14(79 \%)$ tumors, and highly correlated with its mRNA expression $(r=0.7419, P=0.0024)$. Shorter overall survival was significantly associated with higher TERT mRNA levels in MCC patients $(P=0.032)$. Collectively, TERT expression and telomerase activity is widespread in MCC, and may be attributable to TERT promoter mutations and gene amplification. Higher TERT expression predicts poor patient outcomes.

\section{INTRODUCTION}

Merkel cell carcinoma (MCC), a neuroendocrine skin malignancy, is believed to originate from intraepidermal Merkel cells and predominantly occurs in the elderly population or immunocompromised individuals [1-4]. Although rare, the annual incidence of MCC has significantly increased in last decades [14]. Moreover, MCC is aggressive and has a mortality rate up to $33 \%$, higher than that of any other skin tumors including malignant melanoma [3-5]. Immunosuppression, ultraviolet (UV) irradiation and infection of Merkel cell polyomavirus (MCV) have been proposed to contribute to the development of MCC [3-5], however, our current understanding of the disease pathogenesis remains limited. Clearly, profound insights into the MCC pathophysiology are required to develop novel therapeutic strategies for the management and outcome improvement of MCC patients.

Telomerase is a RNA-dependent DNA polymerase responsible for lengthening telomere and silent in most normal human cells with a limited life-span [610]. It is well established that activation of telomerase is an essential step in malignant transformation, and by stabilizing telomere length, telomerase confers 
transformed cells an infinite proliferation potential [610]. Indeed, numerous clinical observations have shown that telomerase activity is detectable in up to $90 \%$ of human malignancies [6-8]. Mechanistically, induction of telomerase reverse transcriptase (TERT) expression, the catalytic component of telomerase, is a key event activating telomerase $[6,9]$. Thus, how cancer-specific TERT expression is achieved has long been an important issue in cancer research, but remains incompletely understood. The accumulated evidence has suggested that genetic factors play an important part in regulating TERT expression. We previously showed that TERT gene was frequently targeted for amplification in carcinogenesis, which contributed to telomerase activation in human malignancies $[11,12]$. It has also been shown that certain single nucleotide polymorphisms increase cancer risk by up-regulating TERT expression and telomerase activity [13]. More recently, somatic TERT promoter mutations namely $\mathrm{C} 228 \mathrm{~T}$ and $\mathrm{C} 250 \mathrm{~T}$ have been identified as novel gain-of-function genetic events in up to $80 \%$ of malignant melanoma and other kinds of cancer [14-25]. All these findings, not only provide insights into telomerase activation in carcinogenesis, but also reveal clinical significance of telomerase/TERT-related assessments in cancer diagnosis and outcome prediction. Furthermore, targeting telomerase or telomere maintenance has been suggested as a novel anti-cancer strategy [26, 27].

Despite numerous existing data on telomerase/ TERT in various types of human malignancies, little is known about these in MCC, and there has been so far only been one published report showing that telomerase activity was detected in 4/4 tumor biopsies from $4 \mathrm{MCC}$ patients and in 3 of 4 cultured MCC cells derived from the above patients [28]. That result indicates widespread telomerase activation in MCC, however, further studies on large cohorts of patients are required to corroborate the finding. Moreover, it is currently unclear how telomerase is activated and how TERT expression is induced in MCC, and whether there exists a relationship between TERT expression and clinical-pathological features of MCC. In the present study, we address these issues by determining TERT expression, promoter mutation, gene amplification, telomerase activity and their clinical-pathological implications in MCC.

\section{RESULTS}

Telomerase activation and association with clinical variables were analyzed together with TERT expression, promoter mutation, and gene amplification using a series of 43 MCCs from 35 patients (Table 1 and Supplementary Table S1) and $6 \mathrm{MCC}$ cell lines.

\section{TERT mRNA expression and telomerase activity in MCC-derived cell lines and tumors from patients with $\mathrm{MCC}$}

A previous study reported detectable telomerase activity in tumor biopsies derived from $4 \mathrm{MCC}$ patients [28], whereas TERT mRNA expression in MCC has not been investigated so far. Therefore, we first determined levels of TERT mRNA and/or telomerase activity in 6 MCC cell lines and 43 tumors 33 formalin-fixed, paraffin-embedded (FFPE) and 15 frozen samples; both FFPE and frozen tumor samples were available from 5 patients] obtained from 35 patients with MCC (Table 1 and Supplementary Table S1). Reverse transcriptionquantitative PCR (RT-qPCR) analyses demonstrated the presence of TERT mRNA at different abundances in all 6 examined MCC cell lines, and 15/15 frozen and 31/33 FFPE tumor specimens (Fig. 1A, C and D, Table 2 and Supplementary Table S2 and S3). Thus, a total of 41 tumors derived from 34 MCC patients (34/35, 97\%) expressed TERT mRNA. Consistent with TERT expression, telomerase activity was detected in all 6 cell lines and $11 \mathrm{MCC}$ frozen tumors analyzed (Fig. 1B and E, Table 2 and Supplementary Table S2). As expected, the cell lines exhibited higher telomerase activity than did MCC tumors (Fig. 1B and E, and Supplementary Table S2). In the activity assay, telomerase-positive HEK-293 cell-derived extract and its heat-treated counterpart were analyzed in parallel as positive and negative controls, respectively. In addition, adjacent normal skin tissues derived from a MCC patient was also included and demonstrated their absence of telomerase activity (data not shown).

\section{TERT promoter mutations in MCC}

The above result reveals a widespread TERT expression and telomerase activation in MCC. Given the recent finding that the UV-related TERT promoter mutation, up-regulating TERT gene transcription, widely occurs in malignant melanoma and other skin cancers [16], we sought to ask whether this was also the case in MCC. $T E R T$ promoter sequencing was performed on $6 \mathrm{MCC}$ cell lines and 43 tumor specimens from 35 patients with MCC. The mutation was found in $1 / 6 \mathrm{MCC}$ cell lines and 5 tumors (MCCT_2a, MCCT_2b, MCCT_17; MCCT_24 and MCCT_29) derived from 4 patients (4/35, 11.4\%) (Fig. 2, Table 2 and Supplementary Table S1), revealing the involvement of this genetic event in the MCC pathogenesis, although the frequency was lower than that in malignant melanoma. The mutant cell line harbored a C250T. One patient (MCCT_2) had the C250T mutation in the tumors from both diagnosis and recurrence. The three remaining mutation-carrying tumors exhibited C250T, C228T and CC242-243TT, respectively. C250T was the 


\begin{tabular}{|c|c|}
\hline Characteristic (no. of informative) & No. of cases \\
\hline No. of tumors & 48 \\
\hline \multicolumn{2}{|l|}{ Gender $(\mathrm{n}=35)$} \\
\hline Male & 15 \\
\hline Female & 20 \\
\hline \multicolumn{2}{|l|}{ Age at diagnosis $(\mathrm{n}=35)$} \\
\hline Median (range) years & $77(20-100)$ \\
\hline$\leq 77$ years & 18 \\
\hline$>77$ years & 17 \\
\hline \multicolumn{2}{|l|}{ Type of lesion $(n=43)$} \\
\hline Primary & 26 \\
\hline Local recurrence & 7 \\
\hline Metastasis & 10 \\
\hline \multicolumn{2}{|l|}{ Primary tumor size $(\mathrm{n}=31)(\mathrm{cm})$} \\
\hline Median (range) $\mathrm{cm}$ & $2.5(0.7-15)$ \\
\hline$\leq 2.5 \mathrm{~cm}$ & 17 \\
\hline$>2.5 \mathrm{~cm}$ & 14 \\
\hline \multicolumn{2}{|l|}{ Primary tumor location } \\
\hline Head and neck & 21 \\
\hline Arm & 7 \\
\hline Other (thigh, gluteal region, groin, leg) & 7 \\
\hline \multicolumn{2}{|l|}{ Survival $(\mathrm{n}=34)$} \\
\hline$<12$ months & 11 \\
\hline $12-60$ months & 15 \\
\hline$>60$ months & 8 \\
\hline \multicolumn{2}{|l|}{ Outcome $(\mathrm{n}=34)$} \\
\hline Alive & 9 \\
\hline Died of other causes & 8 \\
\hline Dead of disease (DOD) & 17 \\
\hline \multicolumn{2}{|l|}{ MCV status $(\mathrm{n}=48)$} \\
\hline Positive & 35 \\
\hline Negative & 13 \\
\hline \multicolumn{2}{|l|}{ Type of materials $(\mathrm{n}=48)$} \\
\hline FFPE & 33 \\
\hline Frozen & 15 \\
\hline
\end{tabular}

FFPE $=$ Formalin fixed paraffin embedded 


\begin{tabular}{|c|c|c|}
\hline Parameter analyzed & MCC & MCC \\
\hline (number of informative MCC samples) & tumors & cell lines \\
\hline Total number of patients & 35 & 6 \\
\hline Total number of samples & 48 & 6 \\
\hline \multicolumn{3}{|l|}{ TERT mRNA expression $(\mathrm{n}=48)$} \\
\hline Positive & $46 / 48$ & $6 / 6$ \\
\hline Negative & 2 & 0 \\
\hline \multicolumn{3}{|l|}{ Telomerase activity $(\mathrm{n}=11)$} \\
\hline Positive & $11 / 11$ & $6 / 6$ \\
\hline Negative & 0 & 0 \\
\hline \multicolumn{3}{|l|}{$T E R T$ promoter sequence $(\mathrm{n}=48)$} \\
\hline Mutated & $5 / 48$ & $1 / 6$ \\
\hline Wild-type & $43 / 48$ & $5 / 6$ \\
\hline \multicolumn{3}{|l|}{ TERT copy numbers $(\mathrm{n}=14)$} \\
\hline Gain & $11 / 14$ & $1 / 6$ \\
\hline Normal & $2 / 14$ & $5 / 6$ \\
\hline Loss & $1 / 14$ & 0 \\
\hline
\end{tabular}

major type of TERT promoter mutations identified in $\mathrm{MCC}$, which is different from most reported malignancies. Of note, for 3 of 4 mutation-carrying tumors, the primary tumor was located in the face and the remaining one was at the temple. Both face and temple are UV-exposed areas in the body and there was a significant difference in TERT promoter mutations between tumors at these sun-exposed and other areas $(P=0.035$, Fisher's exact test $)$.

\section{The TERT gene amplification in MCC tumors}

The TERT gene is localized in chromosomal region 5 p15.33 whereas gains of this region are prevalent in MCC [12, 29, 30]. Because the TERT amplification was previously found in many kinds of cancer $[11,12]$, we examined TERT gene copy numbers in $6 \mathrm{MCC}$ cell lines and 14 patient-derived frozen tumors using qPCR. Patients' peripheral blood leukocytes and TERT-amplified HeLa cell line [12] were used as normal (2 copies/cell) and positive ( 5 copies/cell) controls, respectively. One of 6 cell lines was found to harbor 5 TERT copies/cell and the remaining 5 lines had normal numbers (Table 2 and Supplementary Table S2). Eleven of 14 examined MCC tumors exhibited increased TERT copies ranging from 3 to 12 /cell, whereas 1 of them had only one TERT copy each cell, indicating its deletion (Supplementary Table S2). Normal TERT copy numbers were observed in 2 tumors (Supplementary Table S2). The presence of TERT amplification was not related to anatomic sites of $\mathrm{MCC}$, which was different from the TERT promoter mutation.

\section{Correlation between TERT mRNA levels and TERT gene amplification in MCC tumors}

To see whether the TERT amplification plays a functional role in TERT mRNA expression, we made a correlation analysis between the TERT copy number and its mRNA level in 14 tumors. As shown in Fig. 3 and Supplementary Table S2, higher TERT mRNA expression was significantly correlated with increased TERT copies in primary MCC tumors $(r=0.7419, P=0.0024)$, suggesting a positive effect of the TERT amplification on gene 
transcription.

\section{Relationship of MCV with the TERT promoter mutation, gene amplification or mRNA expression}

MCV is implicated in the pathogenesis of MCC [31], and we were thus interested in the relationship between $\mathrm{MCV}$ and the TERT promoter mutation and TERT expression. In our cohort, 3/6 (50\%) MCC cell lines and 25/35 (71\%) MCC tumors were MCV-positive (Table 1 and Supplementary Table S1 and S2). The one cell line with TERT promoter mutation was negative for MCV. Three of the 4 mutation-carrying MCC tumors were MCVnegative and one was MCV-positive (Supplementary Table S2 and S3). These results suggest that the TERT promoter mutation tends to occur in MCV-negative MCCs (mutations in MCV+ vs - cases: $P=0.0613$, Fisher's exact test). When both cell lines and patients were analyzed together, there was a significant difference in the mutation between tumors with and without $\mathrm{MCV}$ $(P=0.011$, Fisher's exact test). There was no difference in TERT mRNA expression either between $\mathrm{MCV}+$ and - cell lines or patients' tumors. We were unable to perform a correlation analysis on MCV status and TERT gene copies due to too few (only one) MCV-negative tumors.

\section{Clinical relevance of the TERT promoter mutation, gene amplification and mRNA expression in $\mathrm{MCC}$}

Age at diagnosis, gender, tumor size, metastasis and recurrence were not associated with the TERT promoter mutation and gene amplification (Supplementary Table S4). However, higher TERT mRNA expression was more frequently observed in male patients $(P=0.047)$. In 24 evaluable MCC patients, lower levels of TERT mRNA expression in tumors were significantly associated with longer overall survival time $[P=0.032$, Log-rank (MantelCox) test; Fig. 4].

\section{DISCUSSION}

In the present study, we performed a comprehensive analysis on the genetic regulation of TERT expression and
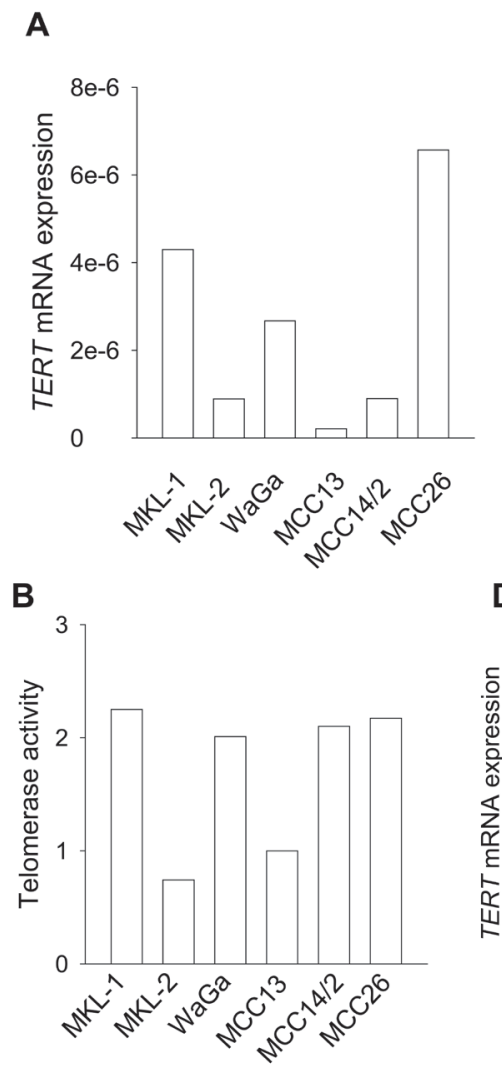

C
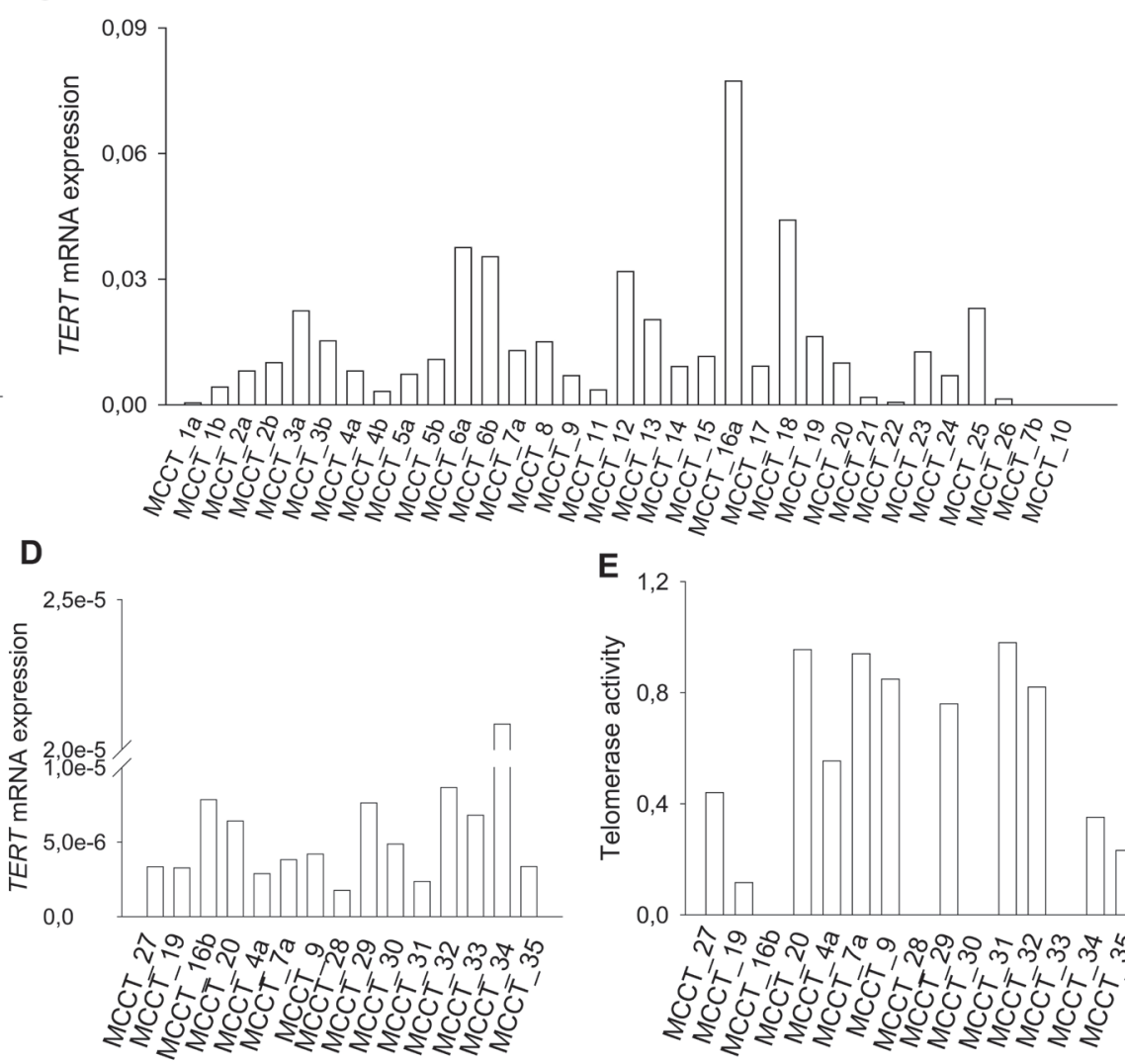

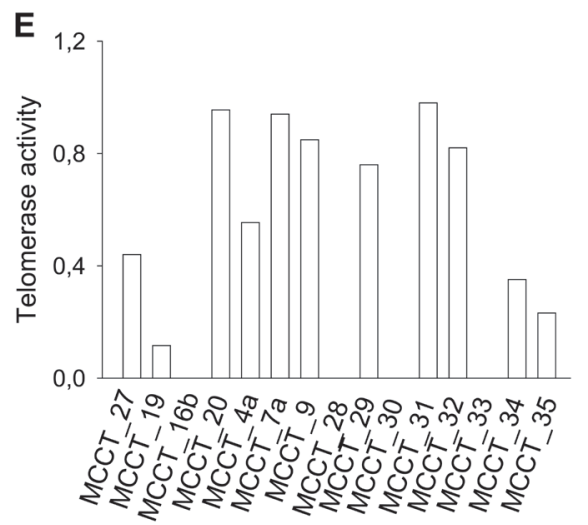

Figure 1: TERT mRNA expression and telomerase activity in MCC cell lines and tumors. Relative TERT mRNA levels were expressed arbitrarily as the ratio of TERT and $18 S$ rRNA (Frozen samples) or ACTB (FFPE samples) CT values. The level of telomerase activity was expressed arbitrarily as folds of that in HEK-293 cells. (A) TERT mRNA expression and (B) telomerase activity in MCC cell lines. (C) TERT mRNA levels in 33 FFPE MCC tumors. (D) TERT mRNA levels in 15 frozen MCC tumors and (E) telomerase activity in those same tumors. Patients MCCT_16b,_28, 30 and_33 had no materials available for telomerase activity assessment. 

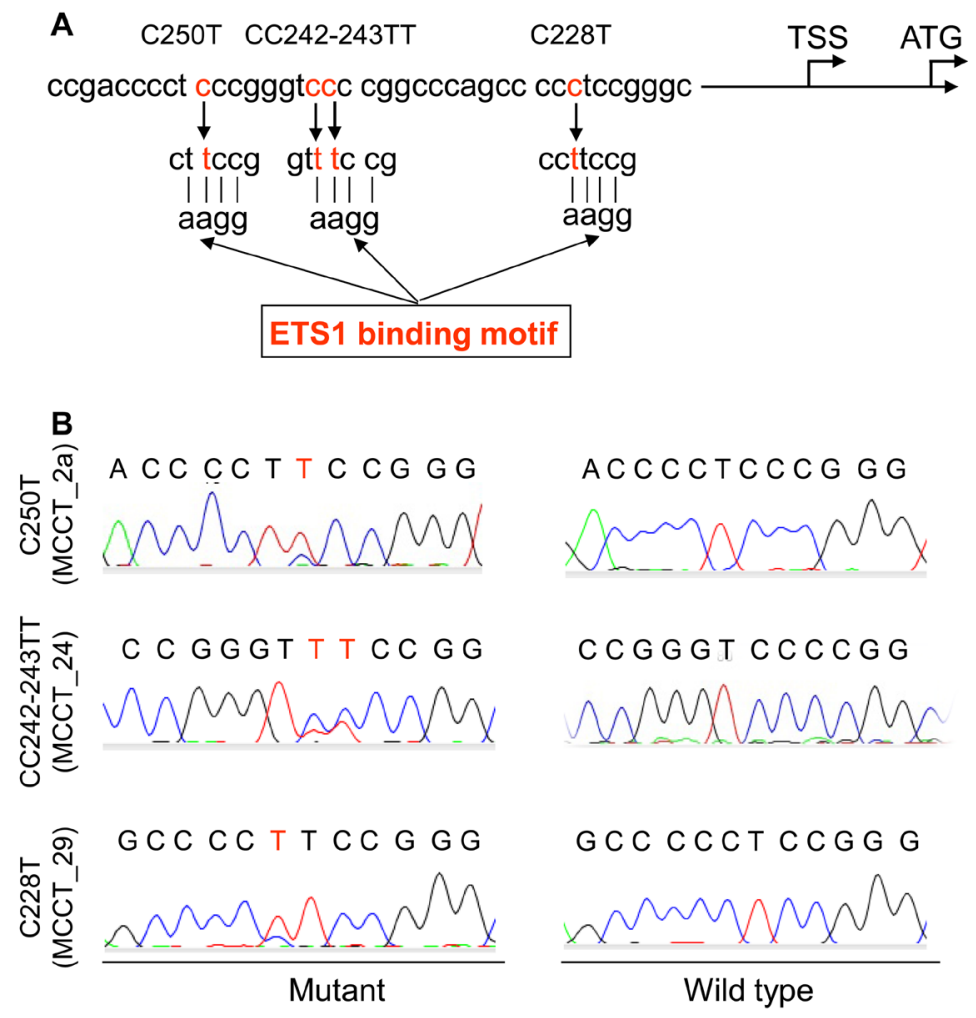

Figure 2: TERT promoter mutations identified in tumors derived from patients with MCC. (A) Schematic illustration showing the location of C228T, CC242-243TT and C250T (in red) in the TERT core promoter. Each of these mutations generates an extra ETS binding motif on the TERT proximal promoter. TSS and ATG: Transcription and translation start sites, respectively (Accession number: AF128893.1). (B) Sequencing chromatographs of the TERT promoter locus in tumor DNA- (left panel) and peripheral blood DNA (right panel) from patients with MCC obtained by Sanger sequencing. Chromatograms shown are C to T transitions at 250 (Top) and 228 (Bottom), and CC to TT alterations at 242-243 (middle) in the TERT promoter.

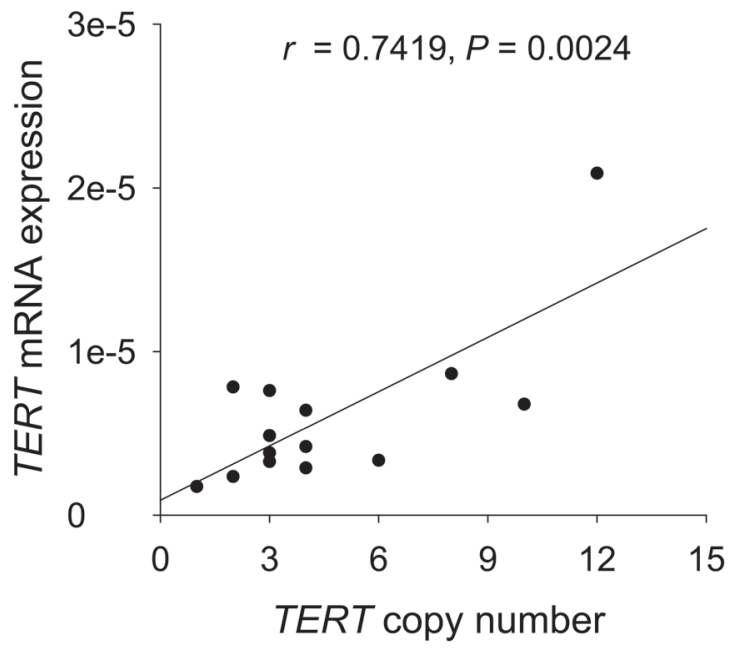

Figure 3: Positive correlation between TERT copy numbers and TERT mRNA abundance in MCC tumors. The scatter plot shows results for TERT mRNA and gene copy number analyses by RT-qPCR in 14 fresh frozen MCC samples. TERT mRNA expression was significantly correlated with TERT copy numbers $(r=0.7419, P=0.0024)$.

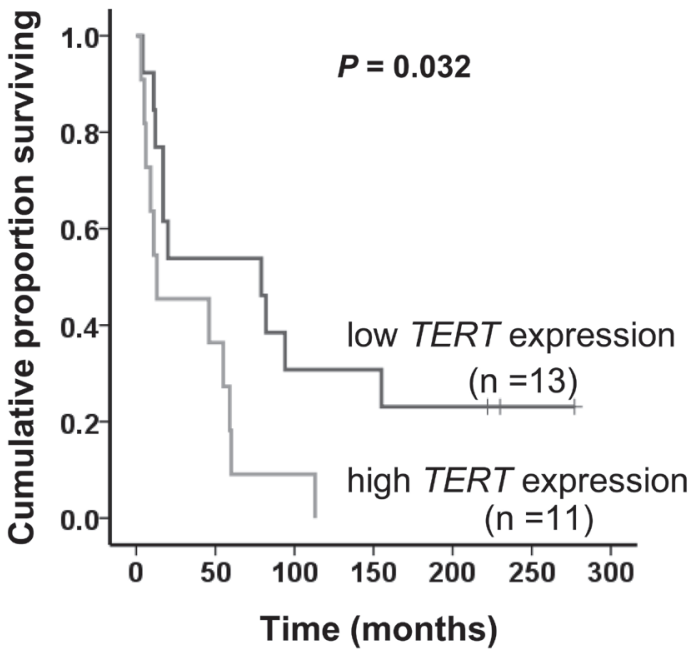

Figure 4: Significant correlation between the TERT mRNA level and overall survival in MCC patients. The level of TERT mRNA expression in 24 evaluable MCC patients was grouped into low and high categories (lower and higher than median values, respectively) and the relationship of patients' overall survival with TERT expression was assessed using Kaplan-Meier plots and significance was determined using log-rank (Mantel -Cox) test. 
its clinical-pathological association in MCC. Our results demonstrate that (i) TERT expression and telomerase activity is highly prevalent in MCC; (ii) TERT promoter mutations are identified in $>10 \%$ of MCC, and most frequently occur at sun-exposed areas and MCV-negative tumors; (iii) The TERT gene amplification is widespread and positively correlated with TERT expression levels in MCC; and (iv) Higher levels of TERT mRNA expression are significantly associated with shorter survival time in MCC patients. These findings provide important insights into the regulatory mechanism underlying telomerase activation in MCC and may be implicated in future MCC management.

The recurrent TERT promoter mutations create de novo ETS binding motifs, thereby facilitating the TERT transcription and activating telomerase, and they have been identified in various types of human malignancies [19]. However, the mutation frequency varies substantially from cancer to cancer. They are widespread in melanoma, cutaneous base and squamous cell carcinoma, bladder and renal pelvic cancer, hepatocellular carcinoma, glioblastoma and certain thyroid cancer, while rare or absent in prostate, lung, breast and digestive track cancer, and hematological malignancies [14-16, 18-21, 23]. In the present study, we identified the TERT promoter mutation in 1/6 MCC cell lines (16.7\%) and 4/35 patients with MCC (11.4\%), which suggests that it is not a rare genetic event in MCC. All the identified mutations, including C250T, C228T and CC242-243TT, lead to gain-offunction via the creation of an extra ETS binding motif [19]. However, the mutation profile observed in MCC is very unique. The $\mathrm{C} 250 \mathrm{~T}$ mutation was predominant in MCC (60\%), which is in sharp contrast to almost all the reported human malignancies where $\mathrm{C} 228 \mathrm{~T}$ is much more prevalent $[15,16,19,25]$. In addition, the CC242-243TT mutation, observed in $1 / 4$ of MCC tumors, is rarely seen in other types of cancer $(<4 \%$ and $0.5 \%$ in melanoma and bladder cancer, respectively). It will be interesting to probe what causes such a difference in the TERT promoter mutation pattern between MCC and other human malignancies. It should be pointed out, however, that we are unable to exclude potential sampling error and thus the result obtained from this cohort of 35 patients is unlikely conclusive. Further studies recruiting more MCC patients are required to confirm the present finding.

Up to $80 \%$ of malignant melanoma harbor TERT promoter mutations and UV irradiation was proposed to result in these mutagenic lesions [15, 16, 25]. UV irradiation is also closely associated with the pathogenesis of $\mathrm{MCC}$, and our findings do support a potential link between the TERT promoter mutation and UV lesions. First, $\mathrm{C}$ to $\mathrm{T}$ and especially $\mathrm{CC}$ to $\mathrm{TT}$ alterations at the TERT promoter, observed in MCC, represent the hallmark of UV-induced DNA mutagenesis. Second, the TERT promoter mutation occurs exclusively in MCC tumors localized at face or temple, sun-exposed areas. These features were similarly observed in malignant melanoma and other skin cancers $[15,16,25]$.

Compared to the TERT promoter mutation, the TERT amplification is more prevalent in MCC. We found that 11 of 14 examined MCC tumors $(79 \%)$ harbored the increased TERT copy number. This result is consistent with previous cytogenetic and $\mathrm{CGH}$ data showing the frequent regional or whole arm gains of $5 \mathrm{p}$ where the TERT locus is localized [4, 29, 30]. Unlike the promoter mutation, the TERT amplification occurs in both sunexposed and other areas, reflecting its irrelevance with UV irradiation [4, 29, 30]. Notably, there exists a highly positive correlation between the TERT gene copy number and its mRNA level, which indicates a functional impact of the TERT amplification on the TERT transcription in MCC. Taken together, the TERT gene amplification plays a significant role in telomerase activation during the development of MCC.

A number of oncogenic viruses target the TERT gene by de-repressing its transcription for telomerase activation $[32,33]$. Because MCV is frequently detected in $\mathrm{MCC}$ and implicated in the disease pathogenesis, we are interested in a potential association between the virus infection and TERT promoter mutation or gene amplification. Intriguingly, the TERT promoter mutation tends to occur in MCV-negative tumors. This is similar to that observed in hepatocellular carcinomas where the TERT promoter mutation is significantly more frequent in patients without hepatitis virus B infection [18]. Owing to the limited number of patients, the relationship between the virus status and TERT amplification remains to be defined. It is currently unclear whether MCV, like other viruses, regulates TERT expression at the transcriptional level. SV40 was shown to activate telomerase in human mesothelial cells via its small T (sT) [34], and given a similar sT encoded by MCV, it could also be the case in the virus-positive MCC. Further experimental studies are required to answer this important question.

Clinical observations suggest that TERT promoter mutations may predict outcomes and associate with aggressive diseases in a number of cancer types [19]. In the present study, we identified $4 \mathrm{MCC}$ patients with the TERT promoter mutation in their tumors, and the number is not sufficient to determine its prognostic or clinical power. Further investigations on a larger cohort of patients are required to address this issue. Nevertheless, a significant association between higher TERT expression and shorter patients' survival observed in the present study indicates that TERT may serve as prognostic marker and be a therapeutic target for MCC.

In summary, the study presented here reveals a widespread TERT expression and telomerase activation in MCC. The TERT gene amplification and promoter mutation may significantly contribute to the de-repression of TERT transcription, whereas higher levels of TERT expression consequently contribute to poor patients' 
outcomes. Moreover, given multi-biological activities of $T E R T /$ telomerase in cancer development and progression, [35] and telomerase-based cancer therapy as a novel anticancer strategy [26], it is worth of determining whether the combination of conventional therapeutic approaches with telomerase inhibitors is capable of improving treatment efficacy and survival in MCC patients.

\section{MATERIALS AND METHODS}

\section{Patient specimens and MCC cell lines}

A total of 48 tumor specimens from 35 patients with MCC were collected and most of them (33/48) had been described in a recent report [36] (Table 1 and Supplementary Table S1). There were 20 female and 15 male patients, with a median age at diagnosis of 77 years (range 20 to 100). Out of the 48 tumors, 33 were obtained as FFPE samples and 15 were fresh-frozen. For 7 patients, matched pairs of primary and recurrent tumors were available. All these MCC specimens exhibited high tumor content with $>80 \%$ tumor cells. The MCC diagnosis was based on histopathological and immunohistochemical examinations. All the patients were followed-up until March 2014 or until death. Detailed clinical and histopathological information is given in Supplementary Table S1. The study was approved by the local Ethics Committee at Karolinska Institutet.

Six MCC cell lines were studied. Three of them were MCV-positive and the remaining 3 were MCVnegative. The MCV-positive cell lines WaGa, MKL-1 and MKL-2 were kindly provided by Drs. Jürgen C. Becker (Medical University of Graz, Graz, Austria), Nancy L. Krett (Northwestern University, Chicago, IL) and Roland Houben (University Hospital Würzburg, Würzburg, Germany), respectively. The MCV-negative MCC cell lines MCC13, MCC14/2 and MCC26 were purchased from CellBank Australia (Westmead, Australia). Cells were grown in RPMI 1640 medium containing 10\% (WaGa, MKL-1 and MKL-2) or 15\% (MCC13, MCC14/2 and MCC26) fetal bovine serum, and $2 \mathrm{ml} \mathrm{L}$-glutamine under $37^{\circ} \mathrm{C} / 95 \%$ air / $5 \% \mathrm{CO}_{2}$.

\section{DNA extraction, TERT promoter sequencing and $T E R T$ gene copy number determination}

Genomic DNA was extracted from FFPE tissues and frozen tumors or cell lines using QIAmp DNA FFPE Tissue kit and Qiagen DNeasy Blood and Tissue kit (Qiagen, Hildane, Germany), respectively. The two common mutations C228T and C250T in the TERT proximal promoter correspond to positions 124 and 146 bp upstream of the ATG site, while the CC242-243TT mutation was at 137 and $138 \mathrm{bp}$. The target region covering these mutations (from $214 \mathrm{bp}$ to $22 \mathrm{bp}$ upstream of the ATG site) were amplified using conventional PCR followed by Sanger sequencing as described [17]. The PCR was performed with the following primer pairs: 5'-CACCCGTCCTGCCCCTTCACCTT-3' and 5'GGCTTCCCACGTGCGCAGCAGGA-3'. The C228T, CC242-243TT and C250T mutations were verified by sequencing from both directions.

TERT gene copy numbers were quantified using qPCR with the primer pair described above. $\beta$-globin gene was PCR-amplified in parallel as a reference for normalization, using the primers 5'-TGTGCTGGCCCATCACTTTG-3' (forward) and 5'-ACCAGCCA-CCACTTTCTGATAGG-3' (reverse). $T E R T$ copy numbers in peripheral blood DNA ( 2 copies/ cells) from MCC patients or normal individuals and HeLa cells ( 5 copies/cell), well-defined in our previous study,[12] were used as normal and positive controls, respectively. Two independent assays were performed and the TERT copy number was determined by mean $\mathrm{Ct}$ values from two independent assays.

\section{RNA extraction and RT-qPCR for TERT mRNA expression}

Total cellular RNA was extracted from frozen and FFPE specimens using mirVana miRNA isolation kit (Life Technology) and modified TriZol method, respectively [36]. qPCR was carried out using an ABI 7900HT Real time PCR System (Applied Biosystems) and Taq Man Gene Expression Assays (Applied Biosystems) for TERT (Hs00972656_m1), ACTB (Hs01060665_g1) and 18S rRNA (Hs99999901_s1). Expression levels of TERT mRNA were calculated from threshold cycle values and normalized to $18 S$ and $A C T B$ values for frozen and FFPE tissues, respectively.

\section{Telomerase activity assessment}

Telomerase activity was determined using a TelotAGGG Telomerase PCR ELISA kit (Roche Diagnostics GmbH, Mannheim, Germany). One microgram protein was used in each assay. Reaction mixtures with human embryonic kidney (HEK)-293 cell protein extracts and their heat-inactivated counterparts were used as positive and negative controls, respectively. Telomerase activity was calculated from the absorbance at optical density (OD) OD450-OD690 and expressed as the folds of that in HEK-293 cells.

\section{MCV detection}

MCV detection was performed using PCR and/or immunohistochemistry [31, 36-38]. The detection of MCV 
status in all FFPE samples has been previously published [36], while all 15 frozen tumors were characterized in this study.

\section{Statistical analyses}

The Pearson correlation analysis was used to determine correlation between the TERT gene copy number and mRNA level. High and low TERT expression groups were defined by the median expression levels of the tumors analyzed. Differences in the TERT promoter mutation frequency and TERT mRNA expression between tumors with gender, clinical stage, tumor size, metastasis and MCV status were determined using Fisher's exact test. Overall survival was illustrated by Kaplan-Meier plots, and significance was calculated by log-rank (Mantel Cox) test. All the tests were two-tailed and computed using Statistica 7.0 software (StatSoft, Tulsa, OK). $P$ values of $<0.05$ were considered as statistically significant.

\section{Disclose any potential conflicts of interest}

The authors disclose no conflicts of interest.

\section{ACKNOWLEDGEMENTS}

The study was supported by grants from the Swedish Cancer Society, the Swedish Research Council, the Cancer Society in Stockholm, the Stockholm County Council and Karolinska Institutet.

\section{REFERENCES}

1. Schrama D, Ugurel S, Becker J. Merkel cell carcinoma: recent insights and new treatment options. Curr Opin Oncol. 2012; 24: 141-149.

2. Bichakjian CK, Lowe L, Lao CD, Sandler HM, Bradford CR, Johnson TM, Wong SL. Merkel cell carcinoma: critical review with guidelines for multidisciplinary management. Cancer. 2007; 110: 1-12.

3. Chang S, Moore P. Merkel cell carcinoma: a virus-induced human cancer. Annu Rev Pathol. 2012; 7:123-144.

4. Kuwamoto S. Recent advances in the biology of Merkel cell carcinoma. Hum Pathol. 2011; 42: 1063-1077.

5. Becker JC, Schrama D, Houben R. Merkel cell carcinoma. Cell Mol Life Sci. 2009; 66: 1-8.

6. Cong YS, Wright WE, Shay JW. Human telomerase and its regulation. Microbiol Mol Biol Rev. 2002; 66: 407-425.

7. Nicholls C, Li H, Wang JQ, Liu JP. Molecular regulation of telomerase activity in aging. Protein Cell. 2011; 2: 726-738.

8. Shay JW, Wright WE: Role of telomeres and telomerase in cancer. Semin Cancer Biol 2011, 21:349-353.

9. Daniel M, Peek GW, Tollefsbol TO. Regulation of the human catalytic subunit of telomerase (hTERT). Gene. 2012; 498: 135-146.

10. Kong F, Zheng C, Xu D. Telomerase as a "stemness" enzyme. Sci China Life Sci. 2014; 57: 564-570.

11. Zhang A, Zheng $\mathrm{C}$, Hou $\mathrm{M}$, Lindvall $\mathrm{C}$, Wallin $\mathrm{KL}$, Angstrom T, Yang X, Hellstrom AC, Blennow E, Bjorkholm M, et al: Amplification of the telomerase reverse transcriptase (hTERT) gene in cervical carcinomas. Genes Chromosomes Cancer 2002, 34:269-275.

12. Zhang A, Zheng $\mathrm{C}$, Lindvall $\mathrm{C}$, Hou $\mathrm{M}$, Ekedahl J, Lewensohn R, Yan Z, Yang X, Henriksson M, Blennow E, Nordenskjöld M, Zetterberg A, Björkholm M, Gruber A, Xu D. Frequent amplification of the telomerase reverse transcriptase gene in human tumors. Cancer Res. 2000; 60: 6230-6235.

13. Melin BS, Nordfjall K, Andersson U, Roos G: hTERT cancer risk genotypes are associated with telomere length. Genet Epidemiol. 2012; 36:368-372.

14. Killela PJ, Reitman ZJ, Jiao Y, Bettegowda C, Agrawal N, Diaz LA, Jr., Friedman AH, Friedman H, Gallia GL, Giovanella BC, Grollman AP, He TC, He Y, Hruban RH, Jallo GI, Mandahl N, Meeker AK, Mertens F, Netto GJ, Rasheed BA, Riggins GJ, Rosenquist TA, Schiffman M, Shih IeM, Theodorescu D, Torbenson MS, Velculescu VE, Wang TL, Wentzensen N, Wood LD, Zhang M, McLendon RE, Bigner DD, Kinzler KW, Vogelstein B, Papadopoulos $\mathrm{N}$, Yan H. TERT promoter mutations occur frequently in gliomas and a subset of tumors derived from cells with low rates of self-renewal. Proc Natl Acad Sci U S A. 2013; 110 : 6021-6026.

15. Huang FW, Hodis E, Xu MJ, Kryukov GV, Chin L, Garraway LA: Highly recurrent TERT promoter mutations in human melanoma. Science. 2013; 339: 957-959.

16. Horn S, Figl A, Rachakonda PS, Fischer C, Sucker A, Gast A, Kadel S, Moll I, Nagore E, Hemminki K, Schadendorf D, Kumar R. TERT promoter mutations in familial and sporadic melanoma. Science. 2013; 339: 959-961.

17. Liu T, Wang N, Cao J, Dinets A, Sofiadis A, Zedenius J, Larsson C, Xu D: The age- and shorter telomere-dependent TERT promoter mutation in follicular thyroid cell-derived carcinomas. Oncogene. 2013; doi: 10.1038/onc.2013.446.

18. Vinagre J, Almeida A, Populo H, Batista R, Lyra J, Pinto V, Coelho R, Celestino R, Prazeres H, Lima L, Melo M, da Rocha AG, Preto A, Castro P, Castro L, Pardal F, Lopes JM, Santos LL, Reis RM, Cameselle-Teijeiro J, SobrinhoSimões M, Lima J, Máximo V, Soares P. Frequency of TERT promoter mutations in human cancers. Nat Commun. 2013; 4: 2185.

19. Heidenreich B, Rachakonda P, Hemminki K, Kumar R. TERT promoter mutations in cancer development. Curr Opin Genet Dev. 2014; 24: 30-37.

20. Wang K, Liu T, Liu L, Liu J, Liu C, Ge N, Wang C, Ren H, Yan K, Hu S, Björkholm, Fan Y, Xu D. TERT promoter mutations in renal cell carcinoma and upper tract urothelial 
carcinoma. Oncotarget. 2014; 5: 1829-1836.

21. Liu T, Liang X, Björkholm M, Jia J, Xu D. The absence of TERT promoter mutations in primary gastric cancer. GENE. 2014; 540: 266-267.

22. Scott G, Laughlin T, Rothberg P. Mutations of the TERT promoter are common in basal cell carcinoma and squamous cell carcinoma. Mod Pathol. 2014; 27: 516-523.

23. Griewank K, Murali R, Schilling B, Schimming T, Möller I, Moll I, Schwamborn M, Sucker A, Zimmer L, Schadendorf D, Hillen U. TERT promoter mutations are frequent in cutaneous basal cell carcinoma and squamous cell carcinoma. PLoS ONE 2013; 8: e80354.

24. Pópulo H, Boaventura P, Vinagre J, Batista R, Mendes A, Caldas R, Pardal J, Azevedo F, Honavar M, Guimarães I, Manuel Lopes J, Sobrinho-Simões M, Soares P. TERT Promoter Mutations in Skin Cancer: the Effects of Sun Exposure and X-Irradiation. J Invest Dermatol. 2014; 134: 2251-2257.

25. Heidenreich B, Nagore E, Rachakonda P, Garcia-Casado Z, Requena C, Traves V, Becker J, Soufir N, Hemminki K, Kumar R. Telomerase reverse transcriptase promoter mutations in primary cutaneous melanoma. Nat Commun. 2014; 5: 3401.

26. Harley CB. Telomerase and cancer therapeutics. Nat Rev Cancer. 2008; 8: 167-179.

27. Boukamp P, Mirancea N. Telomeres rather than telomerase a key target for anti-cancer therapy? Exp Dermatol. 2007; 16: 71-79.

28. Stoppler H, Stoppler MC, Kisiela M, Holzbach A, Moll I, Houdek P, Moll R. Telomerase activity of Merkel cell carcinomas and Merkel cell carcinoma-derived cell cultures. Arch Dermatol Res. 2001; 293: 397-406.

29. Paulson KG, Lemos BD, Feng B, Jaimes N, Penas PF, Bi X, Maher E, Cohen L, Leonard JH, Granter SR, Chin L, Nghiem P. Array-CGH reveals recurrent genomic changes in Merkel cell carcinoma including amplification of L-Myc. J Invest Dermatol. 2009; 129: 1547-1555.

30. Van Gele M, Leonard JH, Van Roy N, Van Limbergen H, Van Belle S, Cocquyt V, Salwen H, De Paepe A, Speleman F. Combined karyotyping, CGH and M-FISH analysis allows detailed characterization of unidentified chromosomal rearrangements in Merkel cell carcinoma. Int J Cancer. 2002; 101: 137-145.

31. Feng H, Shuda M, Chang Y, Moore PS. Clonal integration of a polyomavirus in human Merkel cell carcinoma. Science. 2008; 319:1096-1100.

32. Strååt K, Liu C, Rahbar A, Zhu Q, Liu L, WolmerSolberg N, Lou F, Liu Z, Shen J, Jia J, Kyo S, Björkholm M, Sjöberg J, Söderberg-Nauclér C, Xu D. Activation of telomerase by human cytomegalovirus. J Natl Cancer Inst. 2009; 101:488-497.

33. Bellon M, Nicot C. Regulation of telomerase and telomeres: human tumor viruses take control. J Natl Cancer Inst. 2008; 100: 98-108.
34. Foddis R, De Rienzo A, Broccoli D, Bocchetta M, Stekala E, Rizzo P, Tosolini A, Grobelny JV, Jhanwar SC, Pass HI. SV40 infection induces telomerase activity in human mesothelial cells. Oncogene. 2002; 21:1434-1442.

35. Liu Z, Li Q, Li K, Chen L, Li W, Hou M, Liu T, Yang J, Lindvall C, Bjorkholm M, Jia J, Xu D. Telomerase reverse transcriptase promotes epithelial-mesenchymal transition and stem cell-like traits in cancer cells. Oncogene. 2013; 32: 4203-4213.

36. Xie H, Lee L, Caramuta S, Höög A, Browaldh N, Björnhagen V, Larsson C, Lui W. MicroRNA expression patterns related to merkel cell polyomavirus infection in human merkel cell carcinoma. J Invest Dermatol. 2014; 134: 507-517.

37. Jung H, Choi Y, Choi J, Roh J, Pyon J, Woo K, Lee E, Jang K, Han J, Park C. Detection of Merkel cell polyomavirus in Merkel cell carcinomas and small cell carcinomas by PCR and immunohistochemistry. Histol Histopathol. 2011; 26: 1231-1241.

38. Duncavage EJ, Le BM, Wang D, Pfeifer JD. Merkel cell polyomavirus: a specific marker for Merkel cell carcinoma in histologically similar tumors. Am J Surg Pathol. 2009; 33: 1771-1777. 